\title{
Tingkat Penerimaan Aplikasi Android E-Filing : Analisis Menggunakan Modifikasi Model UTAUT
}

\author{
Thesa Adi Purwanto, Wahyu Nofiantoro \\ Program Pendidikan Vokasi UI \\ Kampus Universitas Indonesia, Depok \\ thesa@vokasi.ui.ac.id, wahyu.nofiantoro@gmail.com
}

Diterima: 15 September 2016. Disetujui: 25 Oktober 2016. Dipublikasikan: Nope mber 2016

\begin{abstract}
Abstrak - Aplikasi e-filing merupakan salah satu bentuk penggunaan Teknologi Informasi (TI) dalam administrasi perpajakan sebagai pengembangan sistem e-Government di Direktorat Jenderal Pajak (DJP). Penelitian ini bertujuan menganalisis faktorfaktor yang mempengaruhi penerimaan penggunaan $e$ filing oleh Wajib Pajak dengan menggunakan Model UTAUT (Unified Theory of Acceptance and Use of Technology) yang dimodifikasi. Penelitian yang dilakukan menggunakan data dari 281 responden Wajib Pajak yang tersebar di kawasan Jakarta, Bogor, Depok, Tangerang dan Bekasi (JaBoDeTaBek). Pengujian keterkaitan antar variabel dilakukan dengan menggunakan Structural Equation Model (SEM) menggunakan program VisualGSCA. Hasil penelitian ini menunjukkan bahwa pengaruh Performance Expectancy (PE) terhadap Behavioral Intention (BI) lebih kuat pada pria dibanding wanita. Hal ini berarti bahwa pria lebih berorientasi pada penyelesaian pekerjaan (kecepatan penyelesaian pekerjaan/tugas) dari pada wanita. Pengaruh Effort Expectancy (EE) terhadap Behavioral Intention (BI) lebih kuat pada wanita dari pada pria. Hal ini berarti bahwa Wajib Pajak wanita lebih berorientasi pada proses, dimana suatu sistem atau teknologi akan mudah dioperasikan setelah dipelajari sebelumnya dengan baik.
\end{abstract}

Kata Kunci : penerimaan teknologi, penggunaan aplikasi, utaut, e-filing.

Electronic Filing System atau e-Filing merupakan suatu cara penyampaian/pelaporan pajak dengan Surat Pemberitahuan (SPT) secara elektronik yang dilakukan secara online yang real time. Penyampaian SPT melalui e-Filing memberikan kemudahan, kepastian hukum, dan meningkatkan pelayanan kepada Wajib Pajak dalam melaporkan dan mempertanggung jawabkan penghitungan jumlah pajak yang terutang. Data SPT yang telah diisi akan langsung dikirim ke data base Direktorat Jenderal Pajak dengan fasilitas internet.

Kemudahan dalam penyampaian SPT secara e-Filing terus dikembangkan dengan harapan dapat meningkatkan kepatuhan Wajib Pajak. Perkembangan penyampaian SPT secara e-Filing kini tidak hanya dapat diakses melalui komputer, melainkan juga dapat diakses melalui smartphone. E-Filing SPT 1770SS (Official) merupakan aplikasi yang dapat dijadikan solusi dalam melakukan pengisian Surat Pemberitahuan Tahunan. Aplikasi ini merupakan aplikasi res mi yang telah diluncurkan Direktorat Jenderal Pajak pada bulan Maret 2015 dan dapat diunduh di berbagai smartphone berbasis android.

Aplikasi resmi dari Direktorat Jenderal Pajak (DJP) ini dikeluarkan dalam rangka memberikan layanan yang prima kepada masyarakat. Wajib Pajak dapat melaporkan kewajiban perpajakannya kapan saja dan dimana saja dengan menggunakan aplikasi ini. Wajib Pajak dapat melihat profil dirinya. Aplikasi in i juga dapat secara otomatis menampilkan data pajak yang telah dipotong dan dilaporkan sebelumnya oleh pemotong pajak dengan cara menekan tombol populate data.

Sebelum Wajib Pajak menyampaikan Surat Pemberitahuan Tahunan Pajak Penghasilan Orang Pribadi, Wajib Pajak harus mengunduh aplikasi pelaporan pajak di smartphone terlebih dahulu. Berikut ini adalah cara mudah untuk mengunduh aplikasi yang telah diberikan oleh Direktorat Jenderal Pajak melalu i aplikasi e-Filing 1770SS:

1. Pastikan bahwa Wajib Pajak menggunakan smartphone berbasis sistem operasi android dan menggunakan formu lir 1770SS dalam pelaporan perpajakan.

2. Pilihlah icon Play Store yang ada pada layar smartphone.

3. Untuk memudahkan pencarian aplikasi pelaporan pajak yang diinginkan, Wajib Pajak bisa mencarinya dengan menuliskan kata " $e$ Filing" di menu pencarian yang ada. Lalu pilih aplikasi e-Filing SPT 1770SS (Official), seperti Gambar 1.

4. Kemudian Wajib Pajak bisa langsung memasang aplikasi ini di smartphone. Setelah proses selesai, Wajib Pajak bisa langsung melaporkan Surat Pemberitahuan Tahunan melalui smartphone. 


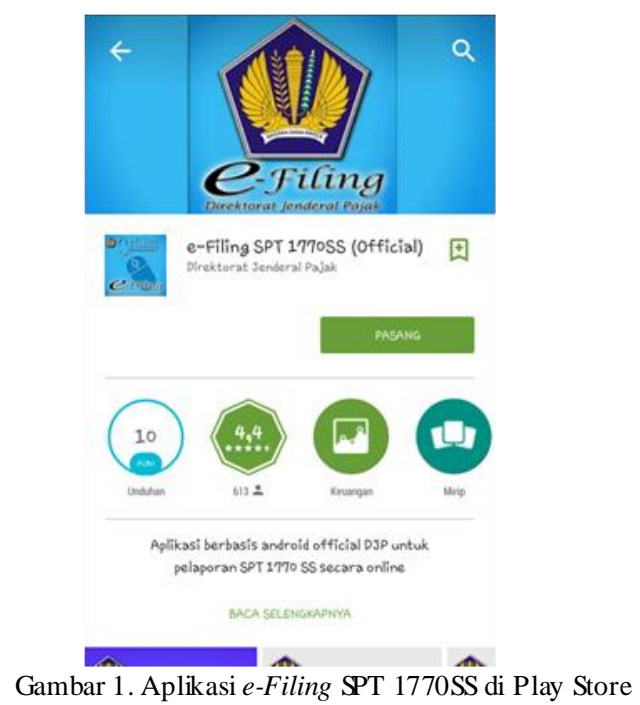

Setelah aplikasi e-Filing 1770SS Direktorat Jenderal Pajak terpasang di smartphone Wajib Pajak, yang perlu dilakukan adalah melakukan tahapan pelaporan pajak seperti berikut:

1. Membuka aplikasi e-Filing 1770SS Direktorat Jenderal Pajak yang telah terpasang di smartphone.

2. Wajib Pajak akan diminta untuk memasukkan Nomor Pokok Wajib Pajak (NPWP) dan password e-Filing untuk dapat mengakses eSPT pada aplikasi ini. Jika sudah memasukkan NPWP dan password, pilih Login.

3. Wajib Pajak dapat melihat profil lengkap diri sebagai Wajib Wajak e-Filing dengan cara memilih menu "Profil". Dengan memilih menu "Profill", akan ditampilkan profil diri sebagai Wajib Pajak yang telah sesuai dengan Master File Wajib Pajak Direktorat Jenderal Pajak. Profil diri tersebut terdiri dari data diri Wajib Pajak, Kantor Pelayanan Pajak (KPP) tempat Wajib Pajak terdaftar, dan Account Representative (AR) yang bertanggung jawab atas perpajakan Wajib Pajak.

4. Jika Wajib Pajak ingin membuat $e-S P T$ yang ada pada aplikasi ini, Wajib Pajak bisa melakukannya dengan cara memilih menu "Buat SPT Baru". Setelah itu isi aplikasi $e-S P T$ dengan benar, lengkap dan jelas.

5. Setelah $e-S P T$ selesai dibuat, Wajib Pajak akan kembali ke menu utama dan melanjutkan tahap selanjutnya yaitu meminta kode verifikasi. Caranya adalah dengan memilih menu "Meminta Kode Verifikasi". Kemudian akan muncul pertanyaan "Apakah Anda yakin ingin meminta kode verifikasi untuk SPT ini?". Pilih "Ya". Kode verifikasi akan dikirim ke alamat email yang digunakan oleh Wajib Pajak pada saat proses registrasi di DJP Online. Kode verifikasi terdiri atas 6 digit kombinasi angka dan huruf.

6. Setelah proses meminta kode verifikasi selesai, Wajib Pajak akan kembali lagi ke menu utama. Lanjutkan tahapan selanjutnya, mengirim Surat Pemberitahuan. Caranya yaitu dengan memilih menu "Kirim SPT". Kemudian masukkan kode verifikasi yang sudah diterima di email.

7. Setelah Surat Pemberitahuan berhasil dikirim, Wajib Pajak akan mendapatkan Bukti Penerimaan Elektronik akan diberikan kepada Wajib Pajak. Menu "Kirim SPT" yang tadinya berwarna biru akan berubah menjadi berwarna hijau jika proses pengiriman Surat pemberitahuan telah berhasil.

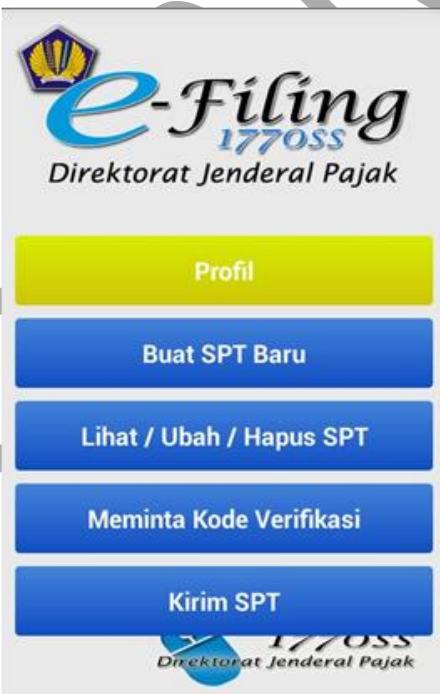

Gambar 2. Menu Utama Aplikasi $e$-Filing SPT 1770SS

\section{TINJAUAN PUSTA KA}

Berdasarkan kajian literatur, dapat diketahui ada tiga golongan penelitian yang dapat menjadi acuan dalam pelaksanaan penelitian ini, yaitu penelitian Model UTAUT pada penerimaan penggunaan sistem yang berjalan secara online, penelitian tentang penggunaan Model UTAUT sebagai model penerimaan pengguna pada sistem $e$ Government, serta penelitian tentang model penerimaan pelaporan pajak secara online baik di Indonesia maupun di luar negeri.

Penelitian dengan menggunakan Model UTAUT sebagai model penerimaan pengguna pada sistem yang dijalan kan secara online telah dilakukan pada beberapa penelitian tentang penggunaan internet banking/online banking [1]. Relevansi penggunaan Model UTAUT pada internet banking disampaikan oleh Gorecha dalam penelitiannya [2] . Selanjutnya, studi kasus penggunaan Model UTAUT untuk melakukan analisis penerimaan pengguna internet banking dilakukan di Cina [3], Australia [4], dan di Timur Tengah [5]. Lebih lanjut, hal ini 
membuat Model UTAUT cukup tepat dan relevan digunakan sebagai model penerimaan pengguna sistem yang dijalan kan secara online [5].

Model UTAUT juga telah digunakan untuk menganalisis model penerimaan pengguna terhadap sistem e-Government yang berhubungan dengan sistem informasi yang memberikan layanan kepada masyarakat. Analisis penerimaan pelajar terhadap sistem e-Government di Kuwait menunjukkan adanya relevansi faktor-faktor da la m Model UTAUT yang digunakan [6]. Senada dengan hal tersebut, penelitian tentang penerimaan pengguna terhadap implementasi e-Government di negara berkembang telah mengusulkan digunakannya variabel ko mbinasi antar model TAM, TAM2, dan UTAUT [7].

Penelitian tentang penerimaan pengguna $e$ Filing sebagai media pelaporan pajak (e-SPT) secara online di Indonesia telah dilakukan oleh berbagai kalangan. Mengacu pada referensi [8] dan [9] yang melakukan analisis terhadap penerimaan e-Filing dengan menggunakan Model TAM. Relevansi model TAM dilakukan tanpa mempertimbangkan faktor demografi secara khusus. Sedangkan penelitian serupa di A merika Serikat yang menyoroti penyebab rendahnya adopsi dan penerimaan sistem e-File, penelitian dilakukan dengan pendekatan Model UTAUT untuk dapat mendapatkan solusi yang spesifik dengan tetap memperhitungkan as pek demografi dan manusia sebagai pihak penerima di dalam sistem itu sendiri [10].

Penelitian yang menggunakan TAM yang dipadukan dengan UTAUT untuk menganalis is penggunaan $e$-Filing untuk menguji faktor-faktor yang mempengaruhi niat Wajib Pajak Orang Pribadi untuk menyampaikan Surat Pemberitahuan (SPT) secara elektronik atau menggunakan $e$-filing menunjukkan bahwa faktor kecemasan terhadap komputer tidak berpengaruh negatif signifikan terhadap niat menyampaikan SPT secara elektronik [11].

\section{METODOLOGI PENELITIAN}

Model yang digunakan dalam penelitian in $\mathrm{i}$ adalah model adopsi teknologi yang dikembangkan oleh Venkatesh et al., yaitu model UTAUT [12]. Pemilihan model ini dilatarbelakangi oleh kondisi riil di lingkungan Wajib Pajak yang mana sebagian besar diantara mereka menggunakan $e$-filing dengan memakai fasilitas jaringan internet di tempat kerja. Oleh karena itu, dapat diambil kesimpulan sementara bahwa fasilitas jaringan internet yang diberikan oleh tempat kerja, berpengaruh terhadap penggunaan $e$-filing oleh Wajib Pajak. Adapun hubungan pengaruh fasilitas yang diberikan dengan penggunaan teknologi, tergambarkan dalam model
UTAUT, yang salah satu variabel latennya adalah facilitating condition [13].

Pada model UTAUT, terdapat empat variabel eksogen (variabel bebas/independen) yang memiliki pengaruh signifikan terhadap penggunaan teknologi [14]. Keempat variabel tersebut adalah sebagai berikut :

a. Performance Expectancy (kepercayaan yang dimiliki individu bahwa kinerjanya akan makin baik apabila menggunakan teknologi),

b. Effort Expectancy (ekspektasi kemudahan dalam penggunaan teknologi),

c. Social Influence (tingkat penerimaan individu terhadap pengaruh orang lain untuk menggunakan teknologi),

d. Facilitating Condition (dukungan sarana /prasarana yang dimiliki individu untuk menggunakan teknologi).

Selain keempat variabel tersebut, [12] juga mengukur pengaruh empat variabel lainnya, yakni jenis kelamin (gender), usia (age), pengalaman (experience), dan kesukarelaan (voluntariness of use) yang memiliki pengaruh langsung yang tidak signifikan terhadap penggunaan teknologi dan internet.

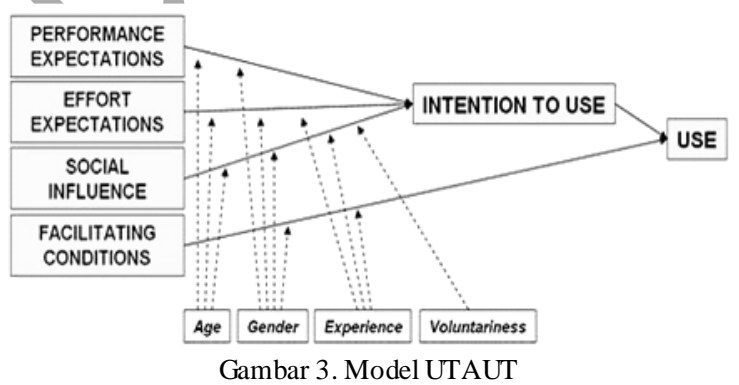

Menurut [15], variabel Voluntariness of Use, age dan experience sebagai variabel moderator pada Model UTAUT tidak perlu dipergunakan apabila individu yang menjadi obyek penelitian berada di lingkungan sekolah. Hal ini sejalan dengan penelitian ini, karena kuesioner yang berbentuk Google form diposting di grup Forum Alumni Vokasi (D3) Perpajakan, sehingga sebagian besar Wajib Pajak yang akan menjadi sampel berada pada rentang umur yang sama dan memiliki tingkat pengalaman yang sama. Dalam penelitian ini, variabel age, experience dan Voluntariness of Use tidak digunakan.

Variabel yang digunakan dalam penelitian in $\mathrm{i}$ terdiri dari variabel eksogen (variabel bebas/ independen) dan variabel endogen (variabel terikat/ dependen). Variabel eksogen dalam penelitian ini adalah Performance Expectancy, Effort Expectancy, Social Influence, Facilitating Condition dan Gender. Variabel endogen yang digunakan adalah Use Behavior dan Actual Usage. 
Berikut ini adalah definisi dari setiap variabel penelitian yang dibuat berdasarkan model UTAUT [16]:

1. Performance Expectancy merupakan tingkat ekspektasi yang dimiliki setiap individu bahwa penggunaan e-filing dapat meningkatkan kepatuhan pelaporan pajak.

2. Effort Expectancy merupakan tingkat ekspektasi kemudahan dalam penggunaan $e$-filing .

3. Social Influence merupakan tingkat penerimaan yang dimiliki individu terhadap saran dari orang lain yang penting bagi dirinya.

4. Facilitating Condition merupakan tingkat kepercayaan individu bahwa tersedia infrastruktur teknis dan organisasi yang mendukung penggunaan $e$-filing .

5. Gender merupakan variabel yang menyatakan jenis ke lamin individu.

6. Behavioral intention merupakan variabel yang menyatakan tingkat penerimaan individu dalam penggunaan $e$-Learning .

7. Actual Use merupakan variabel yang menyatakan tingkat penggunaan e-filing oleh individu.

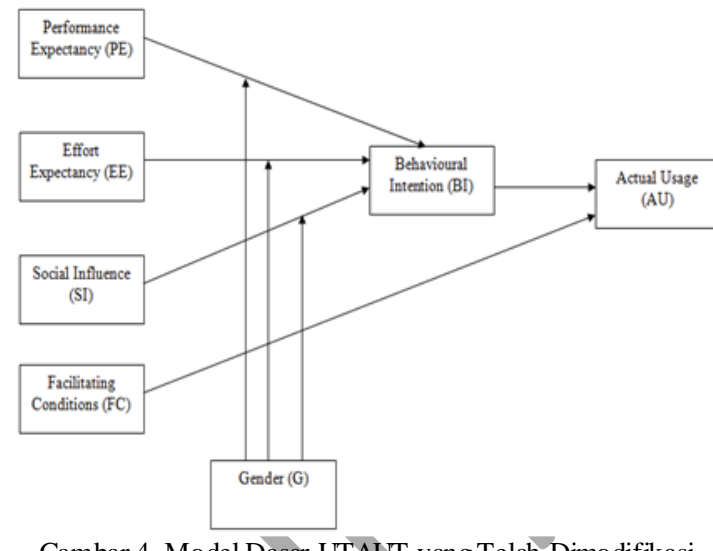

Gambar 4. Model Dasar UTAUT yang Telah Dimodifikasi

Variabel penelitian (variabel laten) diukur dengan menggunakan beberapa indikator (variabel manifes/ observed variable) sebagai alat ukur langsung pada setiap variabel laten. Dalam penelitian ini, indikator yang digunakan merupakan indikator yang diturunkan oleh [12] dari beberapa model yang digunakan pada penelitian-penelitian sebelumnya. Semua variabel penelitian kecuali gender yakni performance expectancy, effort expectancy, social influence, facilitating condition, behavioral intention, dan actual usage diukur dengan beberapa pernyataan sebagai indikatornya. Skala Likert yang terdiri dan angka 1 (sangat tidak setuju) sampai dengan 5 (sangat setuju) digunakan untuk menyatakan persetujuan responden terhadap pernyatan tersebut.

Pengumpulan data penelitian dilakukan dengan menyebarkan kuesioner secara langsung dan tidak langsung kepada seluruh responden. Oleh karena itu, data yang diperoleh merupakan data primer. Pengumpulan data ini dilakukan dalam jangka waktu satu minggu dengan menggunakan Google form yang diposting di grup Forum Alumni Vokasi (D3) Perpajakan.

Analisis data dilakukan dengan menggunakan teknik SEM. Tujuan dari penelitian ini adalah melakukan prediksi mengenai model yang digunakan, maka teknik analisis yang digunakan adalah SEM berbasis component (component based SEM). Data yang diperoleh dari responden kemudian direkapitulasi untuk dapat diolah lebih lanjut. Rekapitulasi data dilakukan dengan menggunakan program Microsoft Excel. Selanjutnya, rekapitulasi data dibedakan menurut keperluan pengolahan dan analisis data. Hal ini dilakukan karena penelitian ini mengadopsi Model UTAUT yang menuntut pemisahan pengolahan data dan analisis terhadap jenis kelamin dari responden.

Selanjutnya, data diolah dengan menggunakan program VisualGSCA. Apabila pengujian dengan menggunakan VisualGSCA membuktikan bahwa model tidak fit dengan data yang ada, maka akan dilakukan modifikasi model. Modifikasi model ini dilakukan terhadap model penerimaan pengguna agar memiliki tingkat kesesuaian yang tinggi dengan data yang ada. Modifikasi model dilakukan dengan cara mengeluarkan indikator yang memiliki nilai loading factor kurang dari 0,5 dan memiliki nilai t hitung yang tidak signifikan (kurang dari 1,96). Indikator tersebut akan dikeluarkan dari analisis untuk melakukan modifikasi model agar memiliki tingkat fitness (kesesuaian) yang lebih baik.

Pengujian validitas dilakukan terhadap indikator (variabel manifest) dan variabel laten secara keseluruhan. Pengujian terhadap validitas indikator dilakukan dengan melakukan uji convergent validity. Convergent validity ini dilakukan dengan menganalisis loading factor masing-masing indikator dari setiap variabel laten. Indikator yang baik (memenuhi syarat convergent validity) indikator yang memiliki nilai loading factor lebih besar dari 0,5 [17].

Uji validitas yang kedua adalah uji validitas terhadap variabel laten, yang dilakukan dengan discriminant validity. Discriminant validity diukur dengan membandingkan nilai akar kuadrat dari A VE (Average Variance Extracted) dengan nilai korelasi antar variabel laten. Variabel laten dikatakan memiliki discriminant validity yang baik jika nilai akar kuadrat dari A VE lebih besar dari nilai korelasi antar variabel laten [17].

AVE diru muskan sebagai berikut :

$$
\mathrm{AVE}=\Sigma \lambda \mathrm{i} 2 /(\Sigma \lambda \mathrm{i} 2+\Sigma(1-\lambda \mathrm{i} 2)]
$$


dengan $\lambda$ i adalah nilai loading factor masing-masing indikator dalam variabel laten.

Selanjutnya, dilakukan uji realibilitas (realibility) untuk masing-masing variabel laten. Hal ini dilakukan dengan menghitung besarnya composite realibility (CR) masing-masing variabel laten, yang dirumuskan sebagai berikut :

$$
\mathrm{CR}=(\Sigma \lambda \mathrm{i}) 2 /[(\Sigma \lambda \mathrm{i}) 2+\Sigma(1-\lambda \mathrm{i} 2)]
$$

dengan $\lambda \mathrm{i}$ adalah nilai loading factor masing-masing indikator dalam variabel laten. Variabel laten dikatakan memiliki composite reliability yang baik jika nilainya lebih besar dari 0,7 [17].

Terdapat banyak cara dan metode yang dapat dilakukan untuk melakukan Uji Kesesuaian Model, antara lain adalah chi-square (x2), GFI, RMSR, RMSEA, NFI, CFI, TL, dan RNI. Sejauh ini, belum ada penelitian khusus yang bertujuan untuk mencari metode uji kesesuaian yang terbaik. Oleh karena itu, penelitian ini menggunakan uji kesesuaian yang sudah banyak digunakan, yaitu pengujian/ pengukuran GFI (Goodness of Fit Index) dan SRMR (Standardized Root Mean square Residual) [17].

Nilai GFI adalah antara 0 dan 1 . Semakin tinggi nilai GFI, maka model semakin fit dengan data yang ada. Model memiliki fitness (kesesuaian yang baik) apabila nilai GFI lebih dari 0,9 dan untuk nilai SRMR mendekati nol [18].

Setelah sebuah model yang diperoleh dinyatakan memiliki tingkat kesesuaian (fitness) yang optimum, selanjutnya dilakukan pengujian hipotesis untuk menyelidiki korelasi antar variabel laten yang menjadi fokus dalam penelitian. Uji Hipotesis dilakukan dengan membandingkan nilai t ( $\mathrm{t}$ - value) yang diperoleh dari perhitungan yang diru muskan dengan :

$$
\mathrm{t}=\text { loading factor } / \text { standard error }
$$

dengan nilai $\mathrm{t}=1,96$ atau $\mathrm{t}=-1,96$ (untuk nilai $\alpha=$ $0,05)$.

Apabila nilai t hitung lebih besar dari nilai $t$, maka hipotesis diterima (antar variabel laten memiliki hubungan kausalitas yang signifikan). Apabila nilai $t$ hitung kurang dari nilai $t$, maka hipotesis ditolak, di mana artinya adalah antar variabel laten memiliki hubungan kausalitas yang tidak signifikan.

\section{HASIL DAN PEMBAHASAN}

Model Dasar UTAUT yang telah dimodifikasi pada Gambar 4 selanjutnya dikembangkan dengan menentukan bentuk korelasi antara faktor UTAUT dengan variabel-variabel indikator SEM.
TABEL 1. KORELASI FAKTOR UTAUT DENGAN VARIABEL SEM

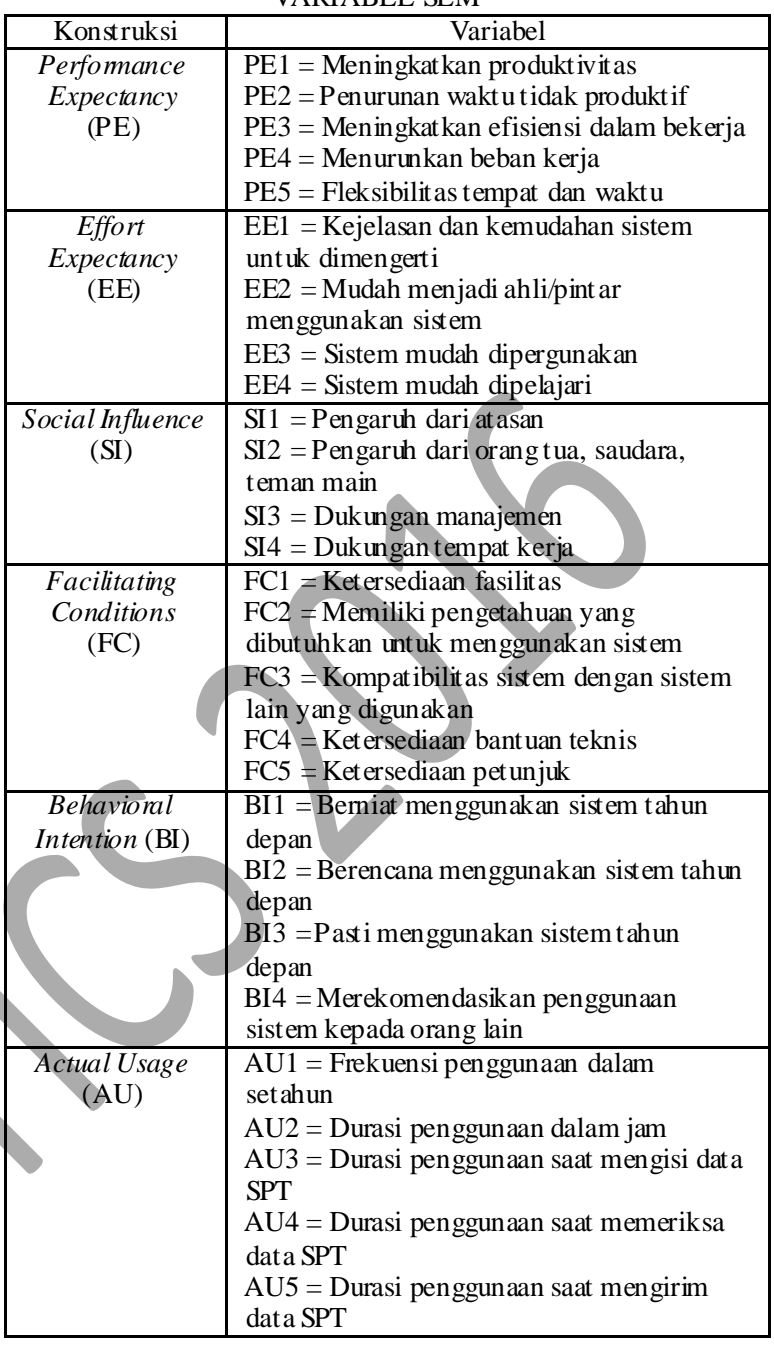

Bentuk diagram untuk Model Penelitian dengan jalur SEM dapat dikembangkan sebagai berikut:

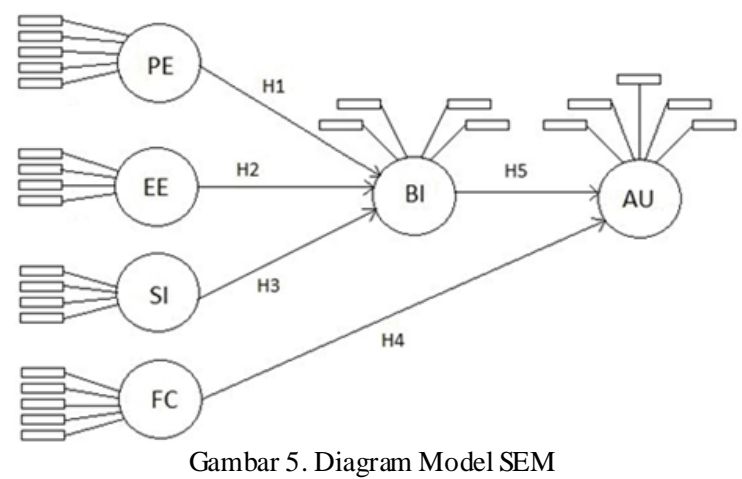

Berdasarkan model penelitian, dapat diketahui bahwa pada penelitian ini, terdapat 5 (lima) hipotesis utama Model UTAUT yang hendak diuji pada masing-masing model penerimaan, yaitu:

1. $\mathrm{H} 1$ : Performance Expectancy (PE) berpengaruh pada Behavioral Intention (BI) 
2. $\mathrm{H} 2$ : Effort Expectancy (EE) berpengaruh pada Behavioral Intention (BI)

3. H3 : Social Influence (SI) berpengaruh pada Behavioral Intention (BI)

4. H4 : Facilitating Condition (FC) berpengaruh pada Actual Usage (AU)

5. $\mathrm{H} 5$ : Behavioral Intention (BI) berpengaruh pada Actual Usage (AU)

Hipotesis tersebut akan diujikan pada model penerimaan pengguna untuk masing-masing kelompok responden yang dikelompokkan berdasarkan kelompok jenis kelamin (responden pria dan wanita) sehingga total hipotesis yang hendak diuji berju mlah 15 buah hipotesis .

Pada penelitian ini, dari jumlah keseluruhan data responden sebanyak 281 buah, 161 (57,3\%) diantaranya berjenis kelamin wanita dan sisanya sebanyak 120 responden $(42,7 \%)$ responden berjenis kelamin pria. Sebaran responden berdasarkan jenis kelamin dapat dilihat pada Gambar 6.
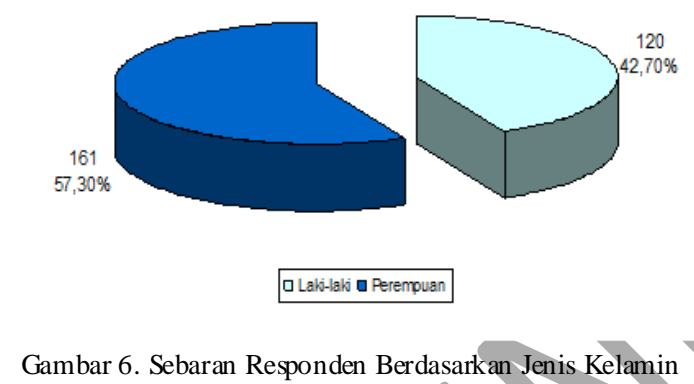

Analisis terhadap model umum dilakukan dengan cara melakukan eksekusi Model untuk semua kuesioner yang masuk. Berdasarkan hasil eksekusi, bentuk model u mu m hasil eksekusi adalah sebagai berikut:

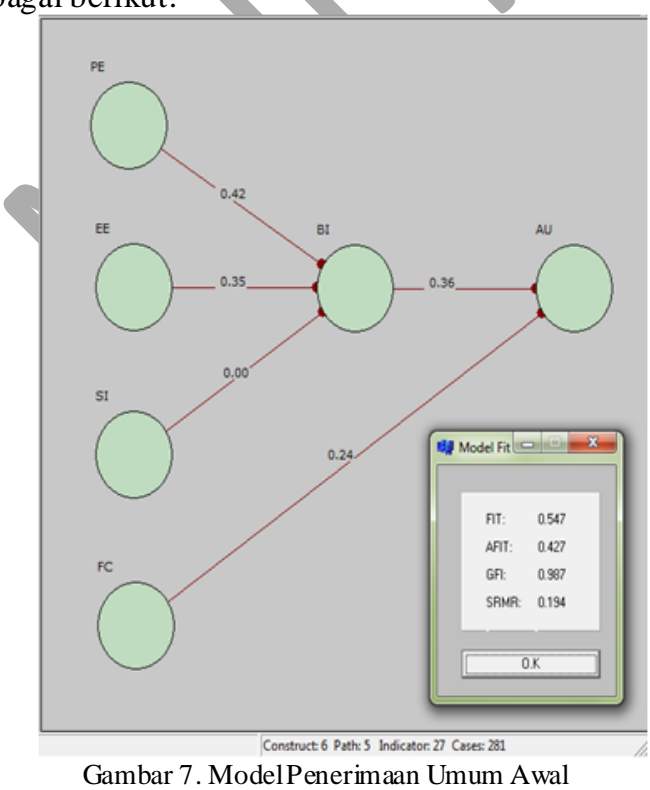


TABEL 3. NILAI CR, AVE, DAN AKAR AVE PADA MODEL PENERIMAAN UMUM AWAL

\begin{tabular}{|l|l|l|l|l|l|l|}
\hline $\begin{array}{c}\text { Vari } \\
\text { abel }\end{array}$ & $(\Sigma \lambda \mathrm{i}) 2$ & $\Sigma \lambda \mathrm{i} 2$ & $\begin{array}{l}\Sigma(1- \\
\lambda \mathrm{i} 2)\end{array}$ & $\mathrm{CR}$ & $\mathrm{AVE}$ & \\
\hline PE & 10,667 & 2,240 & 2,761 & 0,794 & 0,448 & 0,669 \\
\hline $\mathrm{EE}$ & 10,824 & 2,715 & 1,285 & 0,894 & 0,679 & 0,824 \\
\hline SI & 6,554 & 1,864 & 2,136 & 0,754 & 0,466 & 0,683 \\
\hline FC & 11,868 & 2,439 & 2,561 & 0,823 & 0,488 & 0,698 \\
\hline BI & 12,624 & 3,179 & 0,821 & 0,939 & 0,795 & 0,892 \\
\hline AU & 11,202 & 2,346 & 2,654 & 0,808 & 0,469 & 0,685 \\
\hline
\end{tabular}

Berdasarkan Tabel 3 dapat diketahui bahwa semua variabel laten memiliki tingkat $C R$ yang baik, karena memiliki nilai lebih dari 0,7[17]. Selanjutnya, akan diketahui nilai discriminant validity dari masing-masing variabel laten. Berdasarkan Tabel 4 di bawah berikut ini, diketahui bahwa nilai discriminant validity masing-masing variabel laten baik, karena nilai akar AVE lebih tinggi daripada nilai korelasi antar variabel laten lainnya.

TABEL 4. AKAR AVE DAN KORELASI ANTAR VARIABEL LATEN PADA MODEL PENERIMAAN UMUM AWAL

\begin{tabular}{|l|c|c|c|c|c|c|}
\hline- & PE & EE & SI & FC & BI & AU \\
\hline PE & 0,669 & & & & & \\
\hline EE & 0.422 & 0,824 & & & & \\
\hline SI & 0.296 & 0.228 & 0,683 & & & \\
\hline FC & 0.277 & 0.578 & 0.375 & 0,698 & & \\
\hline BI & 0.574 & 0.532 & 0.207 & 0.346 & 0,892 & \\
\hline AU & 0.305 & 0.382 & 0.192 & 0.362 & 0.441 & 0,685 \\
\hline
\end{tabular}

Selanjutnya, indikator yang memiliki loading factor yang belum baik (kurang dari 0,5) yaitu indikator PE5, SI4, FC5 dan AU1 perlu di drop untuk melakukan modifikasi model agar memiliki tingkat fitness (kesesuaian) yang lebih baik. Setelah dilakukan modifikasi model, diketahui model hasil modifikasi adalah sebagai berikut:

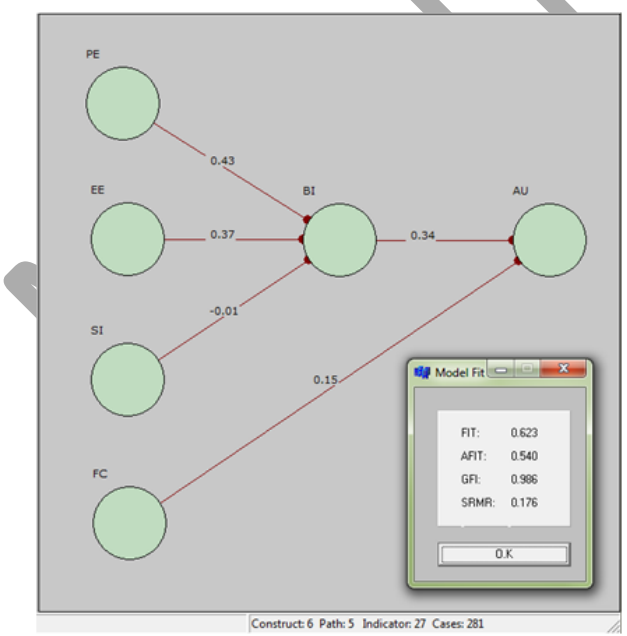

Gambar 8. ModelPenerimaan Umum Hasil Modifikasi

Berdasarkan simulasi model hasil modifikasi, diketahui bahwa terjadi peningkatan kesesuaian Model Struktural, yang ditandai dengan peningkatan nilai FIT. Nilai FIT naik dari 0,547 menjadi 0,623 yang berarti model secara keseluruhan mampu menjelaskan variance dari data sebesar $62,3 \%$. Berdasarkan uji kesesuaian model struktural tersebut, dapat diketahui bahwa model sudah baik, hal ini ditandai dengan nilai GFI (Goodness of Fit Index) sebesar 0,987 (lebih besar dari 0,9) dan nilai SRMR (Standardized Root Mean square Residual) sebesar 0,176 (mendekati nilai 0). Hasil perhitungan loading factor dan $\mathrm{t}$ hitung pada masing-masing indikator dapat dilihat pada Tabel 5.

TABEL 5. MODEL PENGUKURAN UMUM HASIL MODIFIKASI

\begin{tabular}{|c|c|c|c|c|}
\hline Construct & Indicator & Loading & Loading(SE) & t hit ung \\
\hline \multirow{4}{*}{ PE } & PE1 & 0,793 & 0,022 & 9,424 \\
\cline { 2 - 5 } & PE2 & 0,796 & 0,033 & 4,020 \\
\cline { 2 - 5 } & PE3 & 0,565 & 0,067 & 1,022 \\
\cline { 2 - 5 } & PE4 & 0,737 & 0,036 & 5,738 \\
\hline \multirow{4}{*}{ EE } & EE1 & 0,752 & 0,033 & 7,671 \\
\cline { 2 - 5 } & EE2 & 0,831 & 0,019 & 7,996 \\
\cline { 2 - 5 } & EE3 & 0,884 & 0,012 & 10,293 \\
\cline { 2 - 5 } & EE4 & 0,823 & 0,02 & 4,324 \\
\hline \multirow{4}{*}{ SI } & SI1 & 0,751 & 0,041 & 0,211 \\
\cline { 2 - 5 } & SI2 & 0,782 & 0,032 & 1,669 \\
\cline { 2 - 5 } & SI3 & 0,821 & 0,026 & 1,424 \\
\hline \multirow{4}{*}{ FC } & FC1 & 0,713 & 0,033 & 3,090 \\
\cline { 2 - 5 } & FC2 & 0,756 & 0,035 & 1,366 \\
\cline { 2 - 5 } & FC3 & 0,792 & 0,027 & 1,745 \\
\cline { 2 - 5 } & FC4 & 0,763 & 0,023 & 1,889 \\
\hline \multirow{4}{*}{ BI } & BI1 & 0,926 & 0,01 & 17,456 \\
\cline { 2 - 5 } & BI2 & 0,926 & 0,01 & 21,094 \\
\cline { 2 - 5 } & BI3 & 0,944 & 0,007 & 18,339 \\
\cline { 2 - 5 } & BI4 & 0,757 & 0,036 & 11,531 \\
\hline \multirow{4}{*}{ AU } & AU1 & 0,541 & 0,066 & 6,264 \\
\cline { 2 - 5 } & AU2 & 0,904 & 0,016 & 4,080 \\
\cline { 2 - 5 } & AU3 & 0,872 & 0,016 & 2,816 \\
\cline { 2 - 5 } & AU4 & 0,581 & 0,066 & 3,448 \\
\cline { 2 - 5 } & AU5 & 0,793 & 0,022 & 9,424 \\
\hline
\end{tabular}

Selanjutnya dilakukan uji reliability, yang dilakukan dengan melakukan perhitungan composite reliability (CR) dan discriminant validity. Berdasarkan perhitungan, diperoleh $\mathrm{CR}$ untuk masing-masing variabel laten adalah sebagai berikut:

TABEL 6. NILAI CR, AVE, DAN AKAR AVE PADA MODEL PENERIMAAN UMUM HASIL MODIFIKASI

\begin{tabular}{|l|l|l|l|l|l|c|}
\hline $\begin{array}{l}\text { Variabe } \\
1\end{array}$ & $(\Sigma \lambda \mathrm{i}) 2$ & $\Sigma \lambda \mathrm{i} 2$ & $\begin{array}{l}\Sigma(1- \\
\lambda \mathrm{i} 2)\end{array}$ & $\mathrm{CR}$ & AVE & $\sqrt{A V E}$ \\
\hline PE & 8,358 & $\begin{array}{l}2,12 \\
5\end{array}$ & $\begin{array}{l}1,87 \\
5\end{array}$ & $\begin{array}{l}0,81 \\
7\end{array}$ & $\begin{array}{l}0,53 \\
1\end{array}$ & 0,729 \\
\hline EE & $\begin{array}{l}10,82 \\
4\end{array}$ & $\begin{array}{l}2,71 \\
5\end{array}$ & $\begin{array}{l}1,28 \\
5\end{array}$ & $\begin{array}{l}0,89 \\
4\end{array}$ & $\begin{array}{l}0,67 \\
9\end{array}$ & 0,824 \\
\hline SI & 5,541 & $\begin{array}{l}1,85 \\
0\end{array}$ & $\begin{array}{l}1,15 \\
0\end{array}$ & $\begin{array}{l}0,82 \\
8\end{array}$ & $\begin{array}{l}0,61 \\
7\end{array}$ & 0,785 \\
\hline FC & 9,145 & $\begin{array}{l}2,28 \\
9\end{array}$ & $\begin{array}{l}1,71 \\
1\end{array}$ & $\begin{array}{l}0,84 \\
2\end{array}$ & $\begin{array}{l}0,57 \\
2\end{array}$ & 0,757 \\
\hline BI & $\begin{array}{l}12,62 \\
4\end{array}$ & $\begin{array}{l}3,17 \\
9\end{array}$ & $\begin{array}{l}0,82 \\
1\end{array}$ & $\begin{array}{l}0,93 \\
9\end{array}$ & $\begin{array}{l}0,79 \\
5\end{array}$ & 0,892 \\
\hline AU & 8,398 & $\begin{array}{l}2,20 \\
8\end{array}$ & $\begin{array}{l}1,79 \\
2\end{array}$ & $\begin{array}{l}0,82 \\
4\end{array}$ & $\begin{array}{l}0,55 \\
2\end{array}$ & 0,743 \\
\hline
\end{tabular}

Berdasarkan Tabel 6, dapat diketahui bahwa semua variabel laten memiliki tingkat CR yang baik, 
karena memiliki nilai lebih dari 0,7. Selanjutnya, yang perlu dicari adalah nilai discriminant validity dari setiap variabel laten.

TABEL 7. AKAR AVE DAN KORELASI ANTAR VARIABEL LATEN PADA MODEL PENERIMAAN UMUM HASIL MODIFIKASI

\begin{tabular}{|l|l|l|l|l|l|l|}
\hline- & PE & EE & SI & FC & BI & AU \\
\hline PE & 0,729 & & & & & \\
\hline EE & 0.371 & 0,824 & & & & \\
\hline SI & 0.237 & 0.173 & 0,785 & & & \\
\hline FC & 0.240 & 0.564 & 0.328 & 0,757 & & \\
\hline BI & 0.565 & 0.532 & 0.155 & 0.337 & 0,892 & \\
\hline AU & 0.216 & 0.363 & 0.081 & 0.265 & 0.390 & 0,743 \\
\hline
\end{tabular}

Berdasarkan Tabel 7, diketahui bahwa nilai discriminant validity masing-masing variabel laten baik, karena nilai akar AVE lebih tinggi daripada nilai korelasi antar variabel laten lainya. Hal ini menandakan bahwa model sudah cukup baik, karena memenuhi seluruh kriteria kelolosan uji validitas dan reliabilitas. Berdasarkan hasil output excel $t$ hitung dapat dihitung dengan membagi nilai koefisien (Path Coefficient) dengan nilai standar error. Perh itungan dapat dilihat pada Tabel 8.

TABEL 8. PERHITUNGAN KOEFISIEN JALUR ANT AR VARIABEL

MODEL PENERIMAAN UMUM

\begin{tabular}{|l|l|l|l|l|l|l|}
\hline- & $\mathrm{BI}$ & $\mathrm{BI}(\mathrm{SE})$ & $\mathrm{t}$ hitung & $\mathrm{AU}$ & $\mathrm{AU}(\mathrm{SE})$ & t hitung \\
\hline $\mathrm{PE}$ & 0,429 & 0,059 & 7,271 & & & \\
\hline EE & 0,371 & 0,062 & 5,984 & & & \\
\hline SI & $-0,009$ & 0,049 & $-0,184$ & & & \\
\hline FC & & & & 0,151 & 0,074 & 2,041 \\
\hline BI & & & & 0,34 & 0,054 & 6,296 \\
\hline
\end{tabular}

Dari hasil Tabel 8 dapat dilakukan uji hipotes is model penerimaan umu $\mathrm{m}$.

TABEL 9. UJI HIPOTESIS MODEL PENERIMAAN UMUM

\begin{tabular}{|c|l|c|c|}
\hline $\begin{array}{c}\text { Hipo } \\
\text { tesis }\end{array}$ & \multicolumn{1}{|c|}{ Korelasi } & \multicolumn{1}{|c|}{$\begin{array}{c}\mathrm{t} \\
\text { hitung }\end{array}$} & Ket \\
\hline H1a & $\begin{array}{l}\text { Pada model penerimaan umum, } \\
\text { Performance Expectancy (PE) } \\
\text { memiliki pengaruh pada } \\
\text { Behavioral Intention (BI) }\end{array}$ & 7,271 & $\begin{array}{l}\text { Signifikan } \\
\text { dan posit if }\end{array}$ \\
\hline H2a & $\begin{array}{l}\text { Pada model penerimaan umum, } \\
\text { Effort Expectancy (EE) } \\
\text { memiliki pengaruh pada } \\
\text { Behavioral Intention (BI) }\end{array}$ & 5,984 & $\begin{array}{l}\text { Signifikan } \\
\text { dan positif }\end{array}$ \\
\hline H3a & $\begin{array}{l}\text { Pada model penerimaan umum, } \\
\text { Social Influence (SI) memiliki } \\
\text { pengaruh pada Behavioral } \\
\text { Intention (BI) }\end{array}$ & $\begin{array}{l}\text { Pada } \\
\text { Pada model penerimaan umum, } \\
\text { Facilitating Condition (FC) } \\
\text { memiliki pengaruh pada Actual } \\
\text { Usage (AU) }\end{array}$ & $\begin{array}{l}\text { Tidak } \\
\text { signifikan } \\
\text { dan negatif }\end{array}$ \\
\hline H5a & $\begin{array}{l}\text { Pada model penerimaan umum, } \\
\text { Behavioral Intention (BI) } \\
\text { memiliki pengaruh pada Actual } \\
\text { Usage (AU) }\end{array}$ & $\begin{array}{l}\text { Signifikan } \\
\text { dan positif }\end{array}$ \\
\hline
\end{tabular}

Berdasarkan pengujian hipotesis pada variabel laten utama, dapat diketahui bahwa pada model UTAUT secara umum, hubungan antar variabel laten yang dihipotesiskan memiliki pengaruh yang signifikan untuk semua hubungan variabel, kecuali variabel Social Influence (SI) pada Behavioral Intention (BI). Hubungan Social Influence (SI) pada Behavioral Intention (BI) adalah tidak signifikan dan negatif dimana artinya ketika Social Influence (SI) naik, maka Behavioral Intention (BI) menjadi berkurang tetapi tidak signifikan. Berdasarkan hasil modifikasi dan pengujian hipotesis, dapat diketahui bahwa bentuk model penerimaan secara umum tanpa mempertimbangkan jenis kelamin dapat digambarkan sebagai berikut:

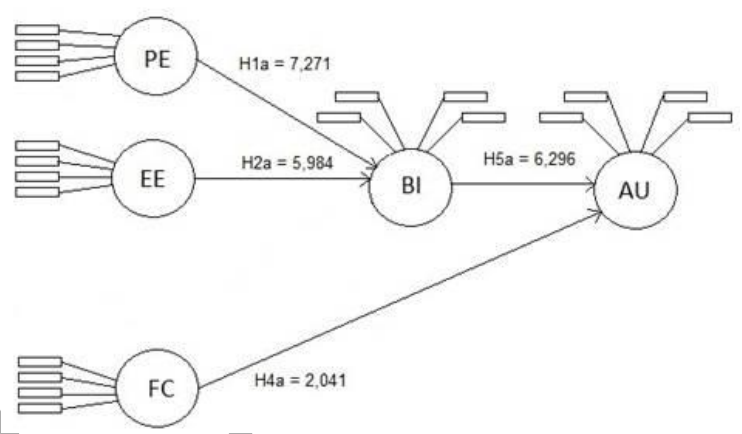

Gambar 9. Bentuk Akhir Model Umum Hasil Modifikasi

Berdasarkan Gambar 9, variabel Social Influence (SI) dihilangkan dari model karena tidak memiliki pengaruh yang signifikan terhadap variabel BI (Behavioral Intention), hal ini menunjukkan bahwa responden dalam menggunakan aplikasi android e-filing 1770 SS tidak dipengaruhi oleh situasi sosial pergaulan dan lingkungan kerjanya. Variabel Performance Expectancy (PE) merupakan variabel yang memiliki pengaruh yang paling signifikan terhadap variabel BI (Behavioral Intention), hal ini menggambarkan responden sangat berharap dengan pemakaian aplikasi android $e$-filing 1770 SS dapat mempersingkat waktu dalam pengisian dan pelaporan Surat SPT, sehingga tingkat kemanfaatan dan kemudahannya sangat terasa. Faktor penerimaan (BI) sangat berpengaruh terhadap aktivitas penggunaan, karena apabila responden telah merasakan kemudahan dan kemanfaatannya, maka tingkat penggunaan aplikasi android e-filing 1770 SS tentu juga akan semakin meningkat.

Selanjutnya untuk model penerimaan pria dan model penerimaan wanita, masing-masing dilakukan tahapan seperti pada model penerimaan umum diatas, tetapi dengan data responden masing-masing.

\section{KESIMPULAN}

Faktor yang berpengaruh terhadap tingkat penerimaan pengguna terhadap penggunaan aplikasi android e-filing $1770 \mathrm{SS}$ berdasarkan penelitian in i adalah faktor Performance Expectancy (PE), Effort Expectancy (EE), Facilitating Conditions (FC) dan 
Gender (G). Hal ini sesuai dengan Model UTAUT yang dikembangkan oleh Venkatesh (Venkatesh, 2003) yang menjadi model rujukan utama dalam penelitian ini. Faktor - faktor yang berpengaruh pada tingkat penerimaan pengguna aplikasi android $e$ filing $1770 \mathrm{SS}$ tersebut kemudian dapat dijelaskan lebih lanjut berdasarkan jenis kelamin.

Berdasarkan jenis kelamin, faktor-faktor yang berpengaruh pada tingkat penerimaan pengguna aplikasi android $e$-filing 1770 SS untuk pria dan wanita berbeda. Pada pria, faktor yang mempengaruhi tingkat penerimaan pengguna aplikasi android e-filing 1770 SS adalah Performance Expectancy (PE), Effort Expectancy (EE), Behavioral Intention (BI) dan Facilitating Condition (FC). Pada wanita, faktor yang mempengaruhi tingkat penerimaan pengguna aplikasi android e-filing 1770 SS adalah Performance Expectancy (PE), Effort Expectancy (EE) dan Behavioral Intention (BI).

Facilitating Condition (FC) tidak menjadi faktor yang mempengaruhi tingkat penerimaan pengguna aplikasi android e-filing 1770 SS pada wanita. Hal ini berhubungan dengan tingkat kenyamanan yang diinginkan oleh responden wanita saat melakukan hal yang membutuhkan konsentrasi yang tinggi seperti dalam mengisi SPT, sehingga sebagian besar responden wanita mungkin merasa lebih nyaman jika aktivitas mengisi SPT dilakukan dengan fasilitas pribadi atau di rumah sendiri yang memungkinkan kenyamanan tetap terjaga.

Pada model penerimaan pria, masing-masing hubungan antar faktor dapat dijelaskan sebagai berikut :

1. Performance Expectancy (PE) memiliki pengaruh yang signifikan dan positif terhadap Behavioral Intention (BI).

2. Effort Expectancy (EE) memiliki pengaruh yang signifikan dan positif terhadap Behavioral Intention (BI).

3. Facilitating Condition (FC) memiliki pengaruh yang signifikan dan positif terhadap Actual Usage (AU).

4. Behavioral Intention (BI) memiliki pengaruh signifikan dan positif terhadap Actual Usage (AU)

Pada model penerimaan wanita, masingmasing hubungan antar faktor dapat dijelaskan sebagai berikut:

1. Performance Expectancy (PE) memiliki pengaruh yang signifikan dan positif terhadap Behavioral Intention (BI).

2. Effort Expectancy (EE) memiliki pengaruh yang signifikan dan positif terhadap Behavioral Intention (BI).

3. Behavioral Intention (BI) memiliki pengaruh signifikan dan positif terhadap Actual Usage (AU).
Pada model penerimaan pengguna terhadap aplikasi android $e$-filing 1770 SS, penggunaan variabel moderating jenis kelamin mengakibatkan adanya perbedaan tingkat pengaruh dari masingmasing faktor yang mempengaruhi tingkat penerimaan pengguna terhadap aplikasi android $e$ filing 1770 SS. Perbedaan tingkat pengaruh pada variabel moderating jenis kelamin adalah: pengaruh Performance Expectancy (PE) terhadap Behavioral Intention (BI) serta pengaruh Facilitating Condition (FC) dan Behavioral Intention (BI) terhadap Actual Usage (AU) lebih kuat pada pria dibanding wanita. Hal ini kemungkinan disebabkan karena pria lebih berorientasi pada penyelesaian pekerjaan (kecepatan penyelesaian pekerjaan/ tugas) daripada wanita (Minton and Schneider, 1908 dalam Venkatesh, 2003). Pengaruh Effort Expectancy (EE) terhadap Behavioral Intention (BI) lebih kuat pada wanita daripada pada pria. Hal ini mengindikasikan bahwa Wajib Pajak wanita kemungkinan lebih berorientasi pada proses [12], di mana suatu sistem atau teknologi akan mudah dioperasikan setelah dipelajari sebelumnya dengan baik. Selain itu, kekhawatiran terhadap kemungkinan terjadinya kesalahan akan berkurang dengan proses pembelajaran yang baik.

Penelitian lanjutan perlu dilakukan untuk mendapatkan model yang lebih dekat ( $f i t)$ dengan realitas data yang ada. Penelitian lanjutan yang diusulkan adalah penelitian untuk menganalisis model penerimaan pengguna dengan metode induktif, yang dilakukan dengan menyelidiki data yang ada dan kemudian dilanjutkan dengan menentukan model penerimaan pengguna/responden terhadap e-filing secara menyeluruh, bukan hanya versi androidnya. Responden diusahakan agar berasal dari latar belakang akademik yang berbedabeda, bertujuan agar setidaknya dapat ditambahkan satu variabel laten baru, yaitu variabel Academic Ability (AA) sebagai moderating variables. Dengan kemampuan akademik yang berbeda-beda tersebut, diperkirakan pengguna akan memperlihatkan usage behaviour yang berbeda pada penenerimaan teknologi berdasarkan Academic Ability yang selanjutnya diperkirakan memiliki pengaruh besar terhadap penggunaan $e$-filing.

\section{REFERENSI}

[1] Yong Guo. 2014. Moderating Effects of Gender in the Acceptance of Mobile SNS - Based on UT AUT Model. 2014 International Conference on Management of eCommerce and e-Government. Pages: 163 - 167.

[2] Gorecha, Anoop. 2005. Application of The Unified Theory of Acceptance and Use of Technology to Internet Banking. The University of Nottingham.

[3] Liu, Gang, Huang, Su-Ping, and Zhu, Xin-Kai. 2008. User acceptance of Internet Banking in an uncertain and risky environment. Proceedings of The 2008 International Conference on Risk Management \& Engineering Management. 381 - 386. 
[4] Yeow, Paul H. P., Yuen, Yee Yen, Tong, David Yoon Kin, Lim, Nena. 2008. User Acceptance of Online Banking Service in Australia. Communication of The IBIMA. 1. 191 - 197.

[5] Al-Qeisi, Kholoud Ibrahim. 2009. Analyzing The Use of UTAUT Model in Explaining an Online Behaviour : Internet Banking Adoption, Ph.D Thesis, Department of Marketing and Branding, Brunel University, UK.

[6] Al Awadhi, Suha, and Morris, Anne. 2008. The Use of The UT AUT Model in the Adoption of E-Government Services in Kuwait. Proceedings of the 41 st Hawaii International Conference on System Sciences. 1 - 11.

[7] Shajari, Maziar, and Zuraini, Ismail. 2010. A Comprehensive Adoption Model of e-Government Services in Developing Countries. IEEE Journal. 10. 548 - 553.

[8] Wiyono, Adrianto Sugiarto. 2008. Evaluasi Perilaku Penerimaan Wajib Pajak Terhadap Penggunaan E-Filing Sebagai Sarana Pelaporan Pajak Secara Online dan Realtime. The Indonesian Journal of Accounting Research. $11,2.117-132$.

[9] Sarjana, Kukuh Wira. 2009. Analisis faktor-faktor yang mempengaruhi minat adopsi e-filling oleh wajib pajak di Indonesia, Master Theses Magister Akuntansi, Pascasarjana FE UGM.

[10] Schaupp, Ludwig Christian, Carter, Lemuria, and Hobbs, Jeff. 2009. E-File Adoption: A Study of U.S. Taxpayers Intentions. Proceedings of the 42nd Hawaii International Conference on System Sciences. 1 - 11.

[11] Wulandari, Fitri. 2015. Analisis Faktor-faktor yang Mempengaruhi Niat Wajib Pajak Orang Pribadi Untuk Menyampaikan Surat Pemberitahuan Secara Elektronik (EFiling), Skripsi Sarjana Akuntansi, Fakultas Ekonomi dan Bisnis UGM.

[12] Venkatesh, V., Morris, M., Davis, G., Davis, F. 2003. User Acceptance of Information Technology : Toward A Unified View. MIS Quarterly. 27, 3. 425-478.

[13] Sara Jeza Alotaibi; Mike Wald. Evaluation of the UTAUT model for acceptable user experiences in Identity Access
Management Systems. 8th International Conference for Internet Technology and Secured Transactions (ICIT ST2013). Pages: $232-237$.

[14] Chia-Lin Hsu; Mu-Chen Chen; Kuo-Chien Chang; Ai-Yun Hsieh. Adopting the extension of UTAUT model to investigate the determinants of e-book adoption. 2014 International Conference on Information Science, Electronics and Electrical Engineering. Volume: 1, Pages: $669-673$.

[15] Ursula Paola Torres Maldonado, Gohar Feroz Khan, Junghoon Moon, Jae Jeung Rho. 2009. E-learning motivation, Students' Acceptance/Use of Educational Portal in Developing Countries: A Case Study of Peru. Fourth International Conference on Computer Sciences and Convergence Information Technology.

[16] Aaron Bere. Exploring Determinants for Mobile Learning User Acceptance and Use: An Application of UTAUT. 2014 11th International Conference on Information Technology: New Generations. Pages: $84-90$.

[17] Ghozali, Imam. 2008. Generalized Struct ured Component Analysis (GSCA) : Model Persamaan Struktural Berbasis Komponen. Semarang : Badan Penerbit Universitas Diponegoro

[18] Hwang, Heungsun. 2007. VisualGSCA 1.0 - A Graphical User Interface Software Program for Generalized Structured Component Analysis. 